tube of callus' of cambial origin was produced. Thus it was not only a question of the development of root initials previously laid down.

Full anatomical details are not yet available, but the possibility is not precluded that repeated cell divisions took place to form cells in an irregular and intercalary manner as distinct from the more regular centripetal and/or centrifugal abscission usually associated with cambial activity.

The new roots frequently emerged in rows, showing a relationship between their point of emergence and the leaf traces. How far is the position of the root, its form and shape, governed by the constraining resistance of the older lignified tissue experienced by the rapidly expanding tube of internal callus ? Can the adventitious root so formed be regarded as parenchyma, moulded into cylindrical shape?

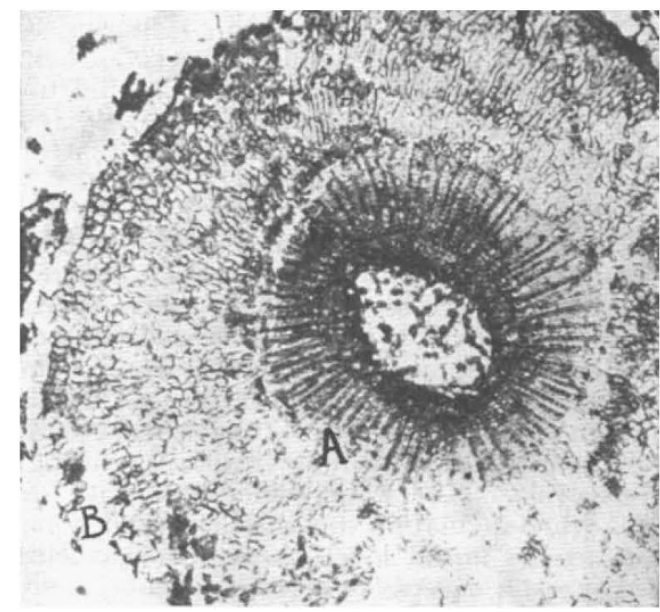

Fig. 3.

Myrtus communis. $A$ TO $B$ SHOWING THE DEVELOPMENT OF PARENCHYMA IN A REGION WITHOUT ROOTS. $\times 40$ diameters. Other details as Fig. 2.

Whilst the cambium may be stimulated at different seasons, including the period of natural quiescence, and whilst root formation may also be induced at various times of the year, the response obtained from one species differs in quality and degree with the season at which treatment is applied and with the co-related nature of the material so selected.

It is difficult to refrain from the attractive speculation that the natural seasonal excitation of the cambium results from the downward translocation of similar substances, formed from young leaves the veins of which are directly connected to the outer portion of the wood. Diffusion to, and excitation of, the cambium could readily take place, as shown by the morphological studies made by Priestley ${ }^{3}$ using the 'strip method'.

I thank Miss W. Hopwood for cutting and preparing sections and Messrs. N. K. Gould and F. C. Brown for the photomicrographic illustrations.

$$
\text { M. A. H. TINCKER. }
$$

Royal Horticultural Society, Wisley, Surrey. April 27.

1 Zimmerman, P. W., and Wilcoxon, F., Contrib. Boyce Thompson Institute, 7, 209 and 439 (1935).

2 Tincker, M. A. H., J. Roy. Hort. Soc., 61, 380 and 510 (1936).

- Priestley, J. H., Pres. Address, Sect. K, Brit. Assoc., York, 1932 ; J. Forestry, 6, 105 '(1932).

\section{Isolation of Carotene from a Wood-Oil}

THE intensive studies of the past few years have illustrated the wide distribution of the carotenoids in Nature, but so far as we are aware, the occurrence of this group of pigments in the oils extractable from timber has not been recorded.

Acacia acuminata, which possesses an extraordinarily hard and heavy stem, is indigenous to Western Australia where, owing to its marked resistivity to termites, it has been extensively used for fencing and similar purposes where this property is of importance. The timber, locally known as 'jam' wood, has a pronounced odour, reminiscent of the common raspberry, Rubus indoeus, and this persists in the timber for years, and in the wood-oil obtained by extraction with light petroleum. A suggestion that carotene might be present in the dark red oil was made by $\mathrm{Hill}^{1}$. It is now confirmed by our isolation of the pigment by chromatographic fraction. ation on alumina.

The adsorption experiment was carried out on the oil, as preliminary analyses had indicated a very small content of saponifiable matter. A number of coloured zones, indicating the presence of at least six carotenoid pigments, were observed. From one of these an extract was obtained which gave $21 \mathrm{mgm}$. of crystalline $\beta$-carotene, m.p. $178^{\circ}$. The amount present in the oil is probably considerably greater than this yield of $0 \cdot 21$ per cent. Dr. R. A. Morton very kindly carried out a spectroscopic examination of the other carotenoid fractions, but reported that they were not pure enough for spectrographic differentiation and identification. Fifty per cent of a non-odoriferous highly fluorescing oil is unadsorbed by the alumina. This is probably hydrocarbon in character. It is likely that the odour of the timber results from a breakdown of carotenoids to $\beta$-ionone, of which it is reminiscent.

No opinion can yet be offered as to whether the high carotenoid content is in any way related to the resistance of the wood towards termites.

V. M. Trikojus.

J. C. DRummond.

Department of Biochemistry, University College, London.

${ }^{1}$ Hill, H. E., J. Roy. Soc. West. Aust., 18, 55 (1931-1932).

\section{Phospholipid Synthesis during Fat Absorption}

WE have recently reported some experiments on the distribution and on the rate of 'organification' of phosphorus in rat's tissues ${ }^{1}$. With the same radioactive technique we have now investigated the synthesis of phospholipids during the absorption of large quantities of fat.

A rat weighing about $250 \mathrm{gm}$. was fed on $5 \mathrm{gm}$. of olive oil and $7.5 \mathrm{mgm}$. of radioactive sodium phosphate having an activity of 1,600 of our radioactive units (R.U.). Nine hours later the rat was bled. The absorption of the ingested phosphate was very complete, as no more than 42 R.U. was found in the gastro-intestinal tube and in the fæces.

The tissues were extracted with alcohol and alcohol plus ether and the extracts purified with anhydrous chloroform. The phospholipids of the liver and gut were further precipitated by acetone plus mag. nesium chloride. The acetone precipitate of the liver has been finally fractionated with cold alcohol. We call the soluble fraction 'lecithin' and the insoluble 